\title{
Cumulative Risk and Internalizing and Externalizing Problems in Early Childhood: Compensatory and Buffering Roles of Family Functioning and Family Regularity
}

\author{
Sara I. Hogye ${ }^{1,2,3}$ (D) Nicole Lucassen ${ }^{4}\left(\mathbb{D} \cdot\right.$ Pauline W. Jansen $^{3,4}(\mathbb{D}) \cdot$ Isabel K. Schuurmans $^{2,5}$ (D) Renske Keizer $^{1}$ (D)
}

Accepted: 20 January 2022 / Published online: 4 March 2022

(c) The Author(s) 2022

\begin{abstract}
In this preregistered study, we studied the extent to which family functioning and family regularity compensated for (compensatory model of resilience, Garmezy et al., Child Development 55:97-111, 1984) and buffered against (risk-protective factor model of resilience, Fergus and Zimmerman, Annual Review of Public Health 26:399-419, 2005) the influence of cumulative risks (CRs) on young children's internalizing and externalizing problems. We conducted path analyses on multi-informant, longitudinal data from 3159 families enrolled in the Generation R Study, a large prospective birth cohort in the Netherlands. Children self-reported on internalizing and externalizing problems at age six. Mothers and fathers reported on 48 CRs between birth and child age five. Mothers reported on family regularity items at child ages two and four, and on family functioning at child age four. CR was positively associated with girls' and boys' internalizing problems, and with boys' externalizing problems. We did not find support for a compensatory or buffering role of family functioning on the association between $\mathrm{CR}$ and children's internalizing or externalizing problems. Our findings suggest that the use of a CR index may be beneficial for identifying children who are at higher risk for developing internalizing and externalizing problems in the early school years, as well as for planning treatment and intervention. Keywords: Cumulative risk, Internalizing problems, Externalizing problems, Family functioning, Family regularity, Early childhood.
\end{abstract}

\section{Introduction}

Children who experience internalizing (e.g., anxiety) and externalizing (e.g., aggressive behavior) problems are more likely to experience a wide range of psychiatric disorders in adolescence and young adulthood (for a review, see Fryers \& Brugha, 2013). Internalizing and externalizing problems arise as early as in preschool age (e.g., Mesman et al., 2001).

Sara I. Hogye

hogye@essb.eur.nl

1 Department of Public Administration and Sociology, Erasmus University Rotterdam, Rotterdam, the Netherlands

2 Generation R Study Group, Erasmus MC University Medical Center Rotterdam, Rotterdam, the Netherlands

3 Department of Child and Adolescent Psychiatry/Psychology, Erasmus MC University Medical Centre Rotterdam, Rotterdam, the Netherlands

4 Department of Psychology, Education and Child Studies, Erasmus University Rotterdam, Rotterdam, the Netherlands

5 Department of Epidemiology, Erasmus MC University Medical Center Rotterdam, Rotterdam, the Netherlands
Accordingly, researchers showed that between 7 and $26 \%$ of the children experience an emotional or behavioral disorder in the first 5 years of life (Egger \& Angold, 2006; Wichstrøm et al., 2012). Factors across various ecological domains (i.e., socio-demographic, parental, contextual) can present risks for developing internalizing and externalizing problems in early childhood (Ackerman et al., 1999; Appleyard et al., 2005). Particularly the co-occurrence of multiple risk factors can harm the well-being and development of children (Evans et al., 2013; Rutter, 1979). However, not all children are at risk for developing internalizing and externalizing problems despite having experienced multiple risk factors (Loukas \& Prelow, 2004; Miller-Lewis et al., 2013). Identifying protective factors that can prevent the onset of internalizing and externalizing problems in the context of early cumulative risk (CR) is essential for prevention and early intervention strategies. Even though the literature points to the family as a whole as an "impressive source of strength" promoting healthy development (Kingon \& O'Sullivan, 2001, p. 116), there is a gap in our knowledge about the buffering role of family-level factors in the associations of CR with internalizing and externalizing problems in early childhood (but see the work of Kysar-Moon (2021) for a recent exception). Given that the family context is one of the 
most predominant environments in preschool age (Flink et al., 2012), the current study examines to what extent regularity and functioning at the family-level can protect children who experience $C R$ between birth and 5 years of age against internalizing and externalizing problems in early childhood.

\section{Cumulative Risk and Maladjustment in Early Childhood}

As mentioned, studies have revealed that children are more vulnerable to maladaptation when they experience multiple (co-occurring) risks as opposed to single risk factors (Evans et al., 2013; Rutter, 1979). A powerful and straightforward approach for operationalizing CR is to dichotomize the exposures to various risk factors (i.e., presence versus absence of risk) and to sum up the dichotomized scores into the CR index (Evans et al., 2013; Rutter, 1979). The CR framework builds on the core assumption that the number rather than the intensity of risk factors experienced is essential for predicting child developmental outcomes (Evans et al., 2013). Despite this approach's limitations, which we touch upon in the discussion section, researchers have reported the strengths of studying the impact of multiple risk factors with this additive CR approach (Chad-Friedman et al., 2020; Evans et al., 2013; Jensen et al., 2015). First, previous studies consistently found that CR indices explain more variance in developmental outcomes than do individual risk factors (Evans et al., 2013; Garmezy et al., 1984; Rutter, 1985; Sameroff et al., 2003). Second, as risk factors often tend to cluster (Ackerman et al., 1999; Appleyard et al., 2005), the CR framework provides a parsimonious and easily interpretable method for studying cooccurring risk factors (Rutter, 1979). Third, when examining a large number of risks, the $\mathrm{CR}$ approach overcomes concerns about collinearity and suppression effects when high correlations among risk factors are present (Ettekal et al., 2019).

Bronfenbrenner's bioecological theory of human development is fundamental to understanding how the accumulation of risk influences child development. The bioecological theory proposes that the psychosocial and physical qualities of the child's immediate environment can critically influence early development (Bronfenbrenner \& Morris, 1998; Evans et al., 2013). Bronfenbrenner and Morris (1998) argued that the cumulative effects of disruptive characteristics of interconnected microsystems (i.e., processes at the mesolevel) can adversely impact human development, likely because these disruptive characteristics tend to "reinforce each other" (p. 1019). Based on empirical support, we believe that it is important to examine risk factors in multiple domains, both within the sociodemographic domain, the parental domain, and the contextual domain (Evans et al., 2013; March-Llanes et al., 2017).

Furthermore, some studies suggest that adversity in early childhood (i.e., between birth and 5 years of age) might be more detrimental to child adjustment than life events and circumstances happening at later developmental phases. For example, Goodman et al. (2011) reported greater mental health problems for children who were exposed to maternal depression as young as age three as compared to children who were exposed at an older age. In another study, Simpson et al. (2012) found that a CR index reflecting environmental unpredictability in childhood from birth to 5 years of age, but not environmental unpredictability between ages six and 16 years, was associated with risky behavior at age 23 years. In a study examining sensitive periods for risk exposure, McFarland (2017) found that poverty experienced in infancy (ages $0-1$ year) and to a lesser extent in early childhood (ages 2-5 years) was associated with later problem behavior. Such associations were not present for poverty experienced in adolescence (age 15; McFarland, 2017). Accordingly, in the current paper, we investigated the impact of the accumulation of risk factors in early childhood (up until 5 years of age) on children's internalizing and externalizing problems.

Still, not all researchers found support for the CR framework. For example, Mäntymaa and colleagues (2012) did not find significant associations between two CRs measured in early life and the likelihood of internalizing and externalizing problems at child age five.

It is important to acknowledge the variation in children's responses to adverse childhood experiences (Shonkoff, 2016). Shonkoff (2016) and the National Scientific Council on the Developing Child (2014) outlined that regardless of the type of stress (positive, tolerable, or toxic) a child may have when facing adversities, the presence of protective, supportive, and dependable relationships play a crucial role in helping children respond better and adapt in the context of early life adversity.

\section{Family-Level Protective Factors}

Fortunately, some children do not develop internalizing and externalizing problems despite experiencing early life adversity - they show resilient adaptation. Resilience refers to the "capacity of a dynamic system to adapt successfully to challenges that threaten the function, survival, or development of the system" (Masten \& Motti-Stefanidi, 2020, p. 98). Children are regarded to be resilient when their development is "better than expected" based on the experienced adversity (Luthar, 2006). Empirical evidence reveals that parental factors, such as parent-child relationship quality and parenting practices (Miller-Lewis et al., 2013), can promote resilience in childhood. In general, the focus in the literature has been on the dyadic interactions between the children and their parents (i.e., proximal processes at the microlevel). For example, in their mixed method study on low-income and relatively ethnically diverse families, Kim and Kochanska (2015) demonstrated that in contexts where parents showed poor and average (but not high) responsiveness, maternal 
power assertion, through child negative adversarial orientation toward the parent, was associated with child internalizing, externalizing, and total behavior problems. Although such studies provide important insights on how dyadic interactions can promote resilience, these studies on resilience often overlooked the importance of processes at the mesolevel. Within the mesolevel, processes across multiple microlevels operate (reflecting upon the interactions between the child and the parents, and between the parents; Bronfenbrenner \& Morris, 1998), which shape structural family factors (such as family regularity) and the quality of relationships within the family as a whole (such as family functioning; Cox \& Paley, 1997). It is surprising that studies focused less on the mesolevel processes given that in early and middle childhood the family environment arguably plays the most salient role in children's socialization, and in children's development (Maccoby, 1992). One of the few studies that did investigate the moderating influence of mesolevel family characteristics in the relationship between adverse childhood experiences and children's problem behavior is the study by Kysar-Moon (2021). In their study, Kysar-Moon showed that family social capital, tapping into the number of helpful family members and the amount of support each family member individually provides, was associated with fewer externalizing problems for children facing adversities.

Our study aims to investigate the role of the family as a whole as a key domain of functioning that could potentially promote adaptive child development in the context of early CRs. The family systems theory views families as dynamic systems, which can buffer against environmental challenges and life events that might negatively influence families (Cox $\&$ Paley, 1997). In line with the bioecological theory, the family systems theory also outlines the beneficial influence of continuity and discontinuity of interactions over time on children's development (Bronfenbrenner \& Morris, 1998; Cox \& Paley, 1997). In terms of Bronfenbrenner's concept of mesotime, we consider stability, consistency, and predictability to be promoting healthy development in the context of early life adversity.

\section{A Focus on Family Functioning and Family Regularity}

Families could promote healthy child development, as well as act as a buffer against CRs through the strength of family relationships, labeled as "family functioning." Family functioning is generally defined as the overall well-being of family members in the domains of problem solving, communication, roles among family members, affective responsiveness, affective involvement, and behavior control (Epstein et al., 2003). Healthy family functioning has been directly linked to children's internalizing problems (Crawford et al., 2011; Kennedy et al., 2015; Velders et al., 2011) and externalizing problems (Davies et al., 2004; Henderson et al., 2006). Furthermore, family functioning was found to buffer the relationships between risk exposure and child outcomes (Masten \& Motti-Stefanidi, 2020; Oliva et al., 2009). For example, family functioning has been related to child well-being in the context of disasters (for a review, see Masten \& MottiStefanidi, 2020). In addition, Oliva et al. (2009) found that high quality family support, indicated by cohesion, communication, affection, and monitoring, buffered the negative consequences of stressful life events on adolescents' behavioral adjustment.

Moreover, besides the beneficial influence of family functioning, family regularity has been shown to be beneficial for children's development. Routines in families can be viewed as "powerful behavior organizer[s] within the family system" (Bao et al., 2019, p. 936; Fiese, 1992) and involve symbolic communication, repeated practices, and meaningful daily interactions (Bao et al., 2019; Spagnola $\&$ Fiese, 2007). The concept family regularity refers to the "consistency of day-to-day family routines," which can take place, for instance, during mealtimes and bedtimes (Rijlaarsdam et al., 2016, p. 782). The maintenance and continuity of these regular routines are beneficial for child development (e.g., Kiser, 2007) and could also play a buffering role for socioemotional and behavioral development in the context of early life adversity. For example, structural family factors, such as mealtime and bedtime routines, have been found to be protective against oppositional behavior of 6-year-old boys who expressed temperamental frustration or anger in infancy (Rijlaarsdam et al., 2016). In another study, Loukas and Prelow (2004) found that family routines of mealtimes, homework times, and bedtimes of 10-14-year-old Latino girls mitigated the influence of multiple risk factors on externalizing problems. Additionally, Thakur and Cohen (2020) found that family routines were associated with childhood trauma-related depressive symptoms in adolescence, representing resilience both in the short term and long term. Along these lines, it is plausible that family environments characterized by structure and regularity could be directly associated with child internalizing and externalizing problems, as well as play a protective (i.e., buffering) role. In this paper, we will therefore investigate whether family functioning and family regularity could promote resiliency in terms of internalizing and externalizing problems in the context of early CR.

\section{The Role of Child Sex}

Considering the consensus on child sex differences in internalizing and externalizing problems, we aim to explore the role of child sex in the associations between $\mathrm{CR}$, family functioning, family regularity, and internalizing and externalizing problems. Literature points to boys developing 
more externalizing problems than girls (e.g., Hammarberg \& Hagekull, 2006; Mayes et al., 2020). Furthermore, research suggests that boys benefit more from regular family routines; Rijlaarsdam et al. (2016) found in their study that family bedtime and mealtime routines were protective against behavioral problems of 6-year-old boys, but not girls, who show temperamental frustration and anger in infancy. Therefore, it might be that boys rather than girls who experience high levels of family regularity report fewer externalizing problems in the context of CR. Moreover, in a study by Freed et al. (2015), results showed that boys who were younger than 13 years of age and who had a parent with bipolar disorder had higher internalizing problems when they experienced lower family cohesion. Considering that higher levels of family cohesion might be associated with lower internalizing problems for boys, it could be that high levels of family functioning would protect boys from developing internalizing difficulties in the context of CR. Given that the empirical base for directional hypothesis is still very weak, we will explore the role of child sex in the associations between CR, family functioning, family regularity, and internalizing and externalizing problems.

\section{Models of Resilience}

In the literature, there is no "gold standard" to conceptualize and operationalize resilience (Kalisch et al., 2017; MillerLewis et al., 2013), and researchers have employed multiple approaches to study the relationships between risks, protective factors, and resilient outcomes (for a review, see Miller-Lewis et al., 2013). The use of different statistical methodologies can make it challenging to directly compare results across studies, as these methodologies often offer insights into different aspects of the risk-moderator-outcome associations (Miller-Lewis et al., 2013). Both personcentered and variable-centered approaches can be used to study resilient outcomes (Luthar, 2006). Person-centered approaches involve prospective analyses in a clinical sample, for instance, to classify vulnerable versus resilient children based on the level of adversity experienced and on the level of protective factors (Luthar, 2006). However, in this paper, using a population-based sample that does not have repeated measures on our variables of interest, we believe that a variable-centered approach is more appropriate. In order to disentangle the extent to which family-level factors can promote healthy development as well as protect against cumulative early life adversity we use two variable-centered methods to examine resilience: (1) a compensatory model of resilience (Garmezy et al., 1984) and a (2) risk-protective factor model of resilience (Fergus \& Zimmerman, 2005; Rutter, 1985).

In the compensatory model of resilience, the CR index and "promotive factors," i.e., factors that theoretically reduce the likelihood of a negative child outcome, together predict the child outcome. In this model, researchers evaluate whether the CR directly influences the child outcome as well as whether the hypothesized promotive factors are (1) directly associated with the outcome, independent of the CR-outcome association (Fergus \& Zimmerman, 2005), and (2) whether the direction of the promotive factor-outcome association is the opposite of the CR-outcome association (Fergus \& Zimmerman, 2005), and (3) whether the promotive factors explain any additional variance in the outcome above and beyond the CR (Buckley \& Chapman, 2020). These three criteria indicate the promotive direct effect of a resource-like variable (such as our familylevel variables), because it "compensates" for the influence of CR on developmental outcomes (Buckley \& Chapman, 2020; Fergus \& Zimmerman, 2005). In this paper, we refer to promotive factors that meet the abovementioned three criteria for a compensatory effect as compensatory factors. Nevertheless, as the compensatory model is limited to identifying direct effects, it might overlook the presence of an interaction between the risks and hypothesized promotive factors.

In the risk-protective factor model of resilience, researchers can evaluate whether a hypothesized protective factor can modify (i.e., weaken) the association between risk and developmental outcome. In this model, an additional statistical interaction term between the CR and protective factor is computed and added to the (compensatory) model. Significant interaction terms could indicate that protective factors in the presence of CR can help children reach "better than expected" developmental outcomes, which researchers recognize as resilient outcomes (Miller-Lewis et al., 2013). In this paper, we refer to protective factors that can modify the CR-outcome relationship as buffering factors. The strength of this model lies in the potential to explain additional variance by the risk $\times$ protective factor interaction in the outcome. Previous research on CR and protective factors indicates support for both the compensatory model and the risk-protective factor model of resilience (Buckley \& Chapman, 2020; Stoddard et al., 2013). In order to investigate the risk-protective factor model, researchers recommend studying samples that are sufficiently large, which can provide the model with sufficient power to be able to detect an interaction between the $\mathrm{CR}$ and the hypothesized protective factor (Miller-Lewis et al., 2013).

Note that certain resource-like variables can promote healthy adaptation in one developmental domain, providing support for the compensatory model, while they might play a different role in another developmental domain, for example by modifying the influence of risk (Luthar, 2006). Therefore, these two methodological approaches are complementary to one another as they can provide us insight into two perspectives on the relationships between $\mathrm{CR}$, family-level variables, and child internalizing and externalizing problems. 


\section{The Current Study}

In the present study, we employed two models of resilience to study the extent to which family-level factors are protective against internalizing and externalizing problems in early childhood in the context of early CR. We investigated children's self-report on internalizing and externalizing problems via the Berkeley Puppet Interview (Measelle et al., 1998). Traditionally, researchers relied on caregiver reports of child internalizing and externalizing problems, arguing for the limited ability of children to identify and distinguish between their own internalizing and externalizing problems. However, it has been recognized that while caregivers and teachers rely on the situational context in which they acknowledge developmental problems, children themselves are also reliable and unique informants of their internalizing and externalizing problems (Rijlaarsdam et al., 2016; Ringoot et al., 2013). Another strength of using child self-report for our outcome variable is that we hereby potentially reduce single source bias, which might be important considering that parental mental health problems are also included in the CR index.

Early life adversity was measured through a CR index that combined the accumulation of parental (i.e., parental age at birth, mental health, and harsh parenting), socio-demographic (i.e., parental education, household income, and unemployment), and contextual (i.e., stressful life events, living conditions, and neighborhood safety) risk factors through a time period encompassing prenatal factors through 5 years of age. Our CR index overcomes two important limitation of prior indices. First, CR indices in previous studies often underestimate the role of paternal mental health (e.g., Chang et al., 2012; Kysar-Moon, 2021; Loukas \& Prelow, 2004) and paternal parenting practices (e.g., Suntheimer \& Wolf, 2020), which are important determinants of child development and problem behavior (Kane \& Garber, 2004; Lereya et al., 2013; Möller et al., 2016; Pinquart, 2017). Moreover, including the mental health or parenting quality of one caregiver but not the other caregiver in two-parent families can lead to missing information on potential risk factors. This is especially unfortunate given that paternal depression has consistently been shown to negatively influence children's development. Specifically, in their systematic review, Sweeney and MacBeth (2016) reported that fathers' depression (depressive symptoms and clinical diagnoses) in the postnatal period was associated with internalizing and externalizing problems in early to late childhood. The current study overcomes this limitation by including risk factors reported by both mothers and fathers, which facilitates the estimation of both maternal and paternal roles in child internalizing and externalizing problems. Second, CR indices in previous studies have not consistently included assessments for neighborhood risk and housing risk. Therefore, in the present study, we included risks for neighborhood deprivation and housing quality in our $\mathrm{CR}$ index. The reason for doing so is that there is consensus in the literature that factors related to poor housing quality and neighborhood safety play a role in children's socioemotional and behavioral development (O'Donnell \& Kingsley, 2020; Rollings et al., 2017; Singh et al., 2019).

The aim of our study is twofold. The first aim was to investigate whether family-level factors can compensate, i.e., "counteract" the influence of $\mathrm{CR}$ on internalizing and externalizing problems, and whether family-level factors could explain variance in the outcomes above and beyond CR. We hypothesized that family-level factors would be directly and negatively related to the two child outcomes, as well as that they explain unique variance in the two child outcomes when controlling for CR. Meeting these three criteria would provide support for the compensatory model of resilience. The second aim was to explore whether family-level factors buffer against internalizing and externalizing problems in the context of CR, indicating resilient development. We hypothesized that family-level factors would moderate (i.e., weaken) the relationships between CR and the two child outcomes, providing support for the risk-protective factor model of resilience.

\section{Methods}

\section{Procedure, Design, and Study Population}

This project is embedded within the Generation R Study, an ongoing prospective birth cohort in the Netherlands, where the participants are studied from infancy onwards (Kooijman et al., 2016). Midwives and obstetricians recruited pregnant women living in the study area, when their delivery date fell between April 2002 and January 2006. The study is in accordance with the Declaration of Helsinki of the World Medical Association and has received approval from the Medical Ethical Committee of the Erasmus University Medical Center in Rotterdam. Parents provided written informed consent for their own participation as well as on behalf of their child.

Generation R Study registered 9749 live births, from which 5957 children participated in the (pre)school phase (please see Online Resource Fig. 1. Flowchart of study population, in the Online Resource Appendix A). Children were included when they completed the BPI at age six $(n=5043)$. Families were excluded when the data quality of the BPI was low $(n=12)$, when more than $50 \%$ of items were missing on the CR index $(n=711)$, when data quality was low of the life events interview (part of the CR index; $n=48$ ), when the family functioning assessment included more than $25 \%$ 
missing items $(n=339)$, when the family regularity assessment included more than $25 \%$ missing items $(n=459)$, and when there were more than $25 \%$ missing items in both family functioning or family regularity assessments $(n=315)$. Participants who are exposed to more risks might be less likely to complete all assessments. A higher threshold for missings on the CR index is considered appropriate as items that make up this index were collected over a period of 5 years, while measures of family functioning were collected at one time point and family regularity were collected at only two time points. A lower threshold for missings on the CR index may instead unintentionally lead to selection bias (Houtepen et al., 2018). Thus, we allowed for $50 \%$ missing items on the total CR index as the missingness could be linked to general stress subsequently related to the risks observed over the 5 years of assessment. The final sample size consisted of 3159 families with full information on the BPI, and sufficient information (on $>50 \%$ of the items) on CR (on $>25 \%$ of the items), family functioning as well as family regularity.

\section{Instruments}

\section{Cumulative Risk Score}

In order to investigate early life adversity, we created a broad $\mathrm{CR}$ index based on maternal and paternal self-reports collected from birth up until child age 5 years. In previous Generation R Studies, comparable "stress" latent factors were implemented with good model fit indices (De Maat et al., 2021; Cortes Hidalgo et al., 2020; Rijlaarsdam et al., 2017; Schuurmans et al., 2021, Manuscript submitted for publication). Single risks within the CR index were previously linked to child internalizing and externalizing problems (see systematic review by Carneiro et al., 2016). Risk assignment was determined based on either a theoretically motivated or statistically defined cutoff values (Suntheimer \& Wolf, 2020).

For information on the cutoff scores of risk items and risk assignment (i.e., yes versus no), please see Online Resource Table 1 in the Online Resource Appendix A. The single risk items can be grouped under five domains, which we present below. Although we examined the broad CR index, and not the separate risk domains, we employed the risk domains for our multiple imputation model (see Analyses).

Life events domain refers to significant and irreversible events in the child's life and included risk items based on the life events interview (based on the Life Events Questionnaire, Oldehinkel \& Hartman, 2003) assessed at child age 9 years (a retrospective report covering the first 9 years of life, e.g., "Is the father/mother or other caregiver still alive?"), and an adapted version of the Social Readjustment Rating Scale questionnaire (SRRS; Holmes \& Rahe, 1967) assessed at child age 3 years (e.g., "Did one of your child's friends move to a new house?"). Data on these measurements were provided by the primary caregiver. Items from the life events interview assessed at child age 9 years were considered for the early CR index when the reported events occurred prior to child age 5 years.

The contextual risks domain refers to environmental risks in and around the child's home and included risk items from the SRRS at child age 3 years (e.g., "Tension at the parents' work that has been felt at home"), life events interview assessed at child age nine (only risks reported prior to age five were included, e.g., "Does your family have financial difficulties or did your family ever have them?"), demographic information on household income at child age 3 and 5 years, overall (un)employment status at 3 years, and maternal and paternal (un)employment status at child age 3 and 5 years. Data on these measurements were provided by the primary caregiver. We combined the risk of maternal and paternal unemployment at 3 years and 5 years into one item in order to indicate whether unemployment by at least one caregiver was present at least at one time point. In the contextual stress domain, we included an assessment of neighborhood deprivation index at birth of child (Municipality of Rotterdam, 2007) physical quality of housing at age 3 years (adapted version of the Infant Toddler Home Observation for Measurement of the Environment; Caldwell \& Bradley, 1984) from an observation report (Rijlaarsdam et al., 2012).

Parental risks domain included the maternal and paternal self-reports on the subscales of depression, anxiety, and interpersonal sensitivity on the Brief Symptom Inventory (BSI; Derogatis \& Melisaratos, 1983) at child age three, and demographic information on maternal and paternal age during pregnancy, and maternal and paternal educational levels at child ages 3 and 5 years. We combined educational levels at ages 3 and 5 years to indicate whether a risk on low maternal educational attainment was present at least once, or whether a risk on low paternal education attainment was present at least once. With regard to paternal age, for those families, in which the mother's partner was not the biological father of the child, we combined the biological father's and the partner's risk on age, characterizing young parenthood, in order to indicate whether risk on early parenthood was present at least by one caregiver.

Interpersonal risks domain refers to (difficulties with) interpersonal relationships in the family system, and the domain included a risk item on the SRRS at child age three ("Problems with marriage relations"), demographic information of family size and marital status at child age 3 and 5 years, and items from the life events interview at child age nine (risks were considered if they happened prior to age five, e.g.; "Has your child ongoing conflict with a family member?"). Data on these measurements were provided by the primary caregiver. We combined the risk on family size at age 3 and 5 years into one item to indicate whether 
a risk on family size was present at least in one assessment time point.

Direct victimization domain refers to physical and emotional harm directed at the child, and the domain included dichotomized total scores based on maternal and paternal self-report of harsh parenting practices (e.g., "I shouted or screamed angrily at him/her"; Parent-Child Conflict Tactics Scale, Straus et al., 1998) at child age 3 years, and risks indicated prior to age five from the life events interview assessed at child age 9 years (e.g., "Did someone ever use physical violence against your child?"). Data on these measurements were provided by the primary caregiver.

In the present study, we summed up dichotomized risk items into one continuous CR index. By dichotomizing each risk factor, the CR index consists of risks of equal weights, which indicates that no assumptions about the relative strength of singular risk factors on the outcome variable are made (Evans et al., 2013). For every set of risk factors in a risk domain, we conducted correlations between the $\mathrm{CR}$ items and between the CR items and the outcomes, moderators, covariates, and auxiliary variables. In the interpersonal risks domain, marital status assessed at 5 years had a correlation of $<0.70$ with ever being divorced; therefore, we removed marital status assessed at 5 years from the $\mathrm{CR}$ index.

\section{Internalizing and Externalizing Problems}

We assessed internalizing and externalizing problems at age six using the Berkeley Puppet Interview (BPI), an ageappropriate interactive interview, where young children described various aspects of their life in a fluid dialogue with two hand puppets (Ablow et al., 2003). The BPI procedure has been described in more detail in the article by Ringoot et al. (2013). During the semi-structured interview, the child engaged in a peer-like conversation with two identical hand puppets, each of whom mentioned opposing statements about themselves and consequently asked the child to indicate which statement described the child best. For example, one puppet said "I am a sad kid," while the other puppet said "I'm not a sad kid." Subsequently, the puppets asked the child to indicate which statement described the child best: "How about you?". The 50-item interview was videotaped, and the items were coded on a 7-point scale, ranging from 1 (very positive) to 7 (very negative). For example, verbal or nonverbal response was coded with 2 ("I'm not a sad kid") or with 6 ("I am a sad kid"). An amplification of the response was coded with 1 or 7 ("I am never [or always] a sad kid"). A toned-down response or a response with a condition was coded with 3 or 5 (e.g., "most of the time," "usually"). Trained research assistants conducted the interviews and coding of the videotaped interviews, independently of each other. Within the Generation R Study sample, Ringoot et al. (2013) has found that children were capable of providing internally consistent responses with regard to the two broadband domains of externalizing and internalizing problems. Their study also showed validity in terms of associations with demographic and socio-economic factors (Ringoot et al., 2013). The internalizing broadband consists of 20 items, and it covers three Symptomatology scales: Depression, Separation Anxiety, and Overanxious. The externalizing broadband consists of 21 items, and it also covers three Symptomatology scales: Oppositional Defiant, Overt Hostility, and Conduct Problems. The average interrater reliability of the scale scores were computed on 20 coders and the intraclass coefficient estimates ranged from 0.96 (Overanxious, Overt Hostility, and Conduct Problems) to 0.98 (Depression, Separation Anxiety). In the current study sample, we found acceptable internal consistency for the two broadband scales, with Cronbach's alpha being 0.70 and 0.76 respectively.

\section{Protective Family Factors}

We assessed family functioning using the General Functioning scale of the McMasters Family Assessment Device (FAD), reported by mothers when their children were 5 years old (Miller et al., 1985). The General Functioning scale is a validated self-report measure (Byles et al., 1988). Primary caregivers indicated their family health on 12 items with a 4-point Likert scale ranging from 1 (disagree strongly) to 4 (agree strongly). Six items referred to healthy functioning, for example "If there are problems, we can count on each other's support," and six items described unhealthy functioning, for example "We avoid talking about worries and problems," which were reverse coded. We computed a weighted sum score of the 12 items, allowing for a $25 \%$ missing item frequency per respondent. The higher the sum score, the healthier the family functioning. In the current study sample, we found good internal consistency with Cronbach's alpha being 0.90 .

We operationalized family regularity based on regular and consistent bedtime at age two and mealtime routines at age four, as indicated by primary caregivers' self-report. Two items - having a bedtime ritual and going to bed at the same time-were proxies for bedtime regularity. An example item is "Has your child gone to bed in the evening at around the same time during the past week?". Respondents indicated their answer as binary categories "Yes" or "No." Additionally, five items relating to child's meal (breakfast, lunch, and dinner) frequency per week and the whole family's meal (breakfast and dinner) frequencies per week were proxies for mealtime regularity. An example item is "How often do you have breakfast around the table together with your child/ children?". Respondents indicated their answers on a 5-point Likert-scale ranging from "never" to "every day." Given that these questions tap into how often different aspects of family 
regularity occur, we created a cumulative family regularity index for the family regularity items. Taking the cumulative approach for the different family regularity items is consistent with previous research applying the cumulative approach for risks and promotive factors (e.g., Stoddard et al., 2013). We allocated a score of 1 to "Yes" responses for the bedtime regularity items, and we allocated a score of 1 to responses "five-six times per week" and "every day" to mealtime regularity items. Subsequently, these scores were summed up into a cumulative family regularity index.

\section{Covariates}

Based on the existing literature on the determinants of emotional and behavioral outcomes and the associations between early life risk and our developmental outcomes (for a review, see Eriksen et al., 2017), we included child's age and sex as covariates in the models. Child age and sex were obtained from hospital and midwife registers.

Furthermore, in all models we adjusted for child ethnicity because we expected CR and child internalizing and externalizing problems to vary by ethnicity (e.g., Hatch \& Dohrenwend, 2007; McLaughlin et al., 2007). Ethnicity was assessed based on the participant's parents' country of birth, reported prenatally using the definition of the Statistics Netherlands (2004). In case one of the parents was born abroad, the country of birth of the participant's mother was taken into account. Based on the classification of the Statistics Netherlands (2004), we distinguished between "Dutch" and "Non-Dutch" (European, North American, Oceanian, Turkish, Moroccan, Indonesian, Cape Verdean, Surinamese, and Antillean) categorization.

\section{Analyses}

Analyses were performed in $\mathrm{R}$ version 4.1.2. We utilized two statistical approaches to investigate the extent to which family-level factors can compensate for or buffer against internalizing and externalizing problems in the context of early CR. Missing items were imputed using multivariate imputations by chained equations in $\mathrm{R}$ (mice package, version 3.12.0, and SemTools package, version 0.5-4, to implement mice in Lavaan), using 32 imputed datasets and 30 iterations (van Buuren \& Groothuis-Oudshoorh, 2011). We imputed missing risk factors using the available information on (1) risk factors specific to the risk domain, (2) domain sum score, (3) internalizing and externalizing sum scores, (4) family regularity sum scores, (5) family functioning sum score, (6) child sex, (7) child age, (8), child ethnicity, and (9) auxiliary variables, i.e., those that can help predict the missing items (Houtepen et al., 2018) but that are not part of the analysis model (e.g., prenatal maternal and paternal depressive symptoms, maternal age at first trimester during pregnancy, prenatal maternal BMI, maternal smoking during pregnancy, parity, gestational age of child at birth, and child weight at birth).

The two models of resilience (compensatory model and risk-protective factor model) were ran using structural equation modeling in $\mathrm{R}$ (Lavaan package, version 0.6-8). All models included the two outcome variables internalizing and externalizing problems. We standardized the internalizing and externalizing continuous problem scores, and we mean-centered the independent variables, to obtain meaningful scales (i.e., a one-point increase on the CR index reflected one additional risk). The main multivariate path models were estimated separately for girls and boys. We accounted for multiple testing by performing false discovery rate corrections on $p$ values, using the Benjamini-Hochberg correction (Benjamini \& Hochberg, 1995). To evaluate the criteria of the compensatory model, we focused on explained variance $\left(R^{2}\right)$, and the magnitude, direction, and significance of path coefficient estimates. We report the pooled results of saturated models (with zero degrees of freedom), where we allowed the residual variances and covariances to vary freely.

First, we tested the compensatory (direct effects) and the risk-protective factor model of resilience for family functioning. In Model 1, we regressed the two outcomes on the covariates child age and child ethnicity, and on the independent variable CR index. In Model 2, we added family functioning to test the compensatory model of resilience. In Model 3, we added an interaction term between the CR index and family functioning to test the risk-protective factor model of resilience.

Second, we tested the compensatory and the risk-protective factor model of resilience for family regularity. In Model 4, we added family regularity to Model 1 to test the compensatory model of resilience. In Model 5, we included an interaction term between the CR index and family regularity to test the risk-protective factor model of resilience.

Third, considering that the main path models were run separately for boys and girls, we conducted supplementary analyses. To test whether the associations of CR, family-level factors, and internalizing and externalizing problems differed significantly between boys and girls, we tested the compensatory and the risk-protective factor models on the whole sample. In Model 6, we regressed the two outcomes on child age, child ethnicity, child sex, the CR index, and an interaction term between child sex and the CR index. In Model 7, we added family functioning and an interaction term between child sex and family functioning. In Model 8, we added one two-way interaction (CR index $\times$ family functioning) and one three-way interaction (child sex $\times$ CR index $\times$ family functioning). In Model 9, we built on Model 6 by adding family regularity and an interaction term between child sex and 
family regularity. In Model 10, we built on Model 9, and added one two-way interaction (CR index $\times$ family regularity) and one three-way interaction (child se $\times \mathrm{CR}$ index $\times$ family regularity).

\section{Results}

\section{Descriptive Results}

Descriptive statistics of child and family characteristics can be viewed in Table 1. In our population-based sample, boys experienced relatively higher levels of externalizing problems than girls, and girls experienced relatively higher levels of internalizing problems than boys. The overall CRs in our sample were relatively low, with boys having slightly more risks on average than girls. Moreover, both girls and boys experienced similar levels of healthy family functioning and high family regularity. We reported correlations between the study variables in the Online Resource Appendix A (Online Resource Table 2).

\section{Main Results}

The output of the main analyses regarding the associations between CR, family functioning, family regularity, and internalizing and externalizing problems are reported in Table 2 (for boys) and in Table 3 (for girls), and the output of the supplementary analyses can be viewed in Online Resource Appendix A, Online Resource Table 3. All significant results that we describe below passed the false rate discovery correction using the Benjamini-Hochberg method, unless otherwise specified. Non-response analyses can be viewed in the Online Resource Appendix B.

\section{Associations Between CR, Family Functioning, Family Regularity, and Children's Internalizing Problems}

Accounting for child age and ethnicity, the findings of Model 1 in Table 2 show that CR was positively associated with internalizing problems for boys $(\beta=0.03, p<0.001)$. The pooled $R^{2}$ for Model 1 was 0.02 . As shown in Table 3, CR was also positively associated with internalizing problems for girls $(\beta=0.04, p<0.001)$ after we accounted for child age and ethnicity. The pooled $R^{2}$ for Model 1 for girls was 0.04. Supplementary analysis (Online Resource

Table 1 Descriptive statistics of sample characteristics $(\mathrm{N}=3159)$

\begin{tabular}{|c|c|c|c|c|c|c|c|}
\hline \multirow{2}{*}{\multicolumn{2}{|c|}{ Child characteristics }} & Boys & & & Girls & & \\
\hline & & Median $(I Q R)^{a}$ & Min-max ${ }^{c}$ & $N(\%)$ & Median $(I Q R)^{a}$ & Min-max ${ }^{c}$ & $N(\%)$ \\
\hline \multicolumn{2}{|l|}{ Age (in years) } & $6.01(0.30)^{\mathrm{b}}$ & $5.04-8.92$ & $1548(49.00)$ & $6.01(0.31)^{\mathrm{b}}$ & $4.93-9.04$ & $1611(51.00)$ \\
\hline \multicolumn{2}{|l|}{$\begin{array}{l}\text { Internalizing prob- } \\
\text { lems }\end{array}$} & $\begin{array}{l}35.00(28.00- \\
44.00)\end{array}$ & 11.00-78.00 & $1548(49.00)$ & $\begin{array}{l}36.00(29.00- \\
45.63)\end{array}$ & 19.00-92.00 & $1611(51.00)$ \\
\hline \multicolumn{2}{|l|}{$\begin{array}{l}\text { Externalizing } \\
\text { problems }\end{array}$} & $\begin{array}{l}29.00(24.15- \\
38.00)\end{array}$ & $10.00-106.00$ & $1548(49.00)$ & $\begin{array}{l}27.00(23.00- \\
32.00)\end{array}$ & $14.00-84.00$ & $1611(51.00)$ \\
\hline \multirow[t]{3}{*}{ Ethnicity } & Dutch & & & 1105 (34.98) & & & $1142(36.15)$ \\
\hline & Non-Dutch & & & 417 (13.20) & & & 442 (13.99) \\
\hline & Missing & & & $26(0.82)$ & & & $27(0.85)$ \\
\hline \multirow{2}{*}{\multicolumn{2}{|c|}{ Family characteristics }} & Boys & & & Girls & & \\
\hline & & Median $(I Q R)^{a}$ & Min-max ${ }^{c}$ & $N(\%)$ & Median $(I Q R)^{a}$ & Min-max ${ }^{c}$ & $N(\%)$ \\
\hline \multirow[t]{6}{*}{ Cumulative risk $^{\mathrm{d}}$} & Index & $4.00(2.00-6.00)$ & $0.00-22.00$ & $1548(49.00)$ & $4.00(2.00-6.00)$ & $0.00-19.00$ & $1611(51.00)$ \\
\hline & Life events ${ }^{\mathrm{e}}$ & $1.00(0.00-2.00)$ & $0.00-6.00$ & & $1.00(0.00-2.00)$ & $0.00-5.00$ & \\
\hline & Contextual risks ${ }^{\mathrm{e}}$ & $1.00(0.00-2.00)$ & $0.00-8.00$ & & $1.00(0.00-2.00)$ & $0.00-8.00$ & \\
\hline & Parental risks ${ }^{\mathrm{e}}$ & $1.00(0.00-2.00)$ & $0.00-9.00$ & & $1.00(0.00-2.00)$ & $0.00-8.00$ & \\
\hline & Interpersonal risks ${ }^{\mathrm{e}}$ & $0.00(0.00-1.00)$ & $0.00-4.00$ & & $0.00(0.00-1.00)$ & $0.00-5.00$ & \\
\hline & $\begin{array}{l}\text { Direct } \\
\text { victimization }^{\mathrm{e}}\end{array}$ & $0.00(0.00-1.00)$ & $0.00-5.00$ & & $0.00(0.00-1.00)$ & $0.00-4.00$ & \\
\hline \multicolumn{2}{|l|}{ Family functioning } & $3.58(3.17-3.92)$ & $1.75-4.00$ & $1548(49.00)$ & $3.58(3.25-3.92)$ & $1.92-4.00$ & $1611(51.00)$ \\
\hline \multicolumn{2}{|l|}{ Family regularity } & $6.00(5.00-6.00)$ & $2.00-7.00$ & $1548(49.00)$ & $6.00(5.00-6.00)$ & $1.00-7.00$ & $1611(51.00)$ \\
\hline
\end{tabular}


Table 2 Associations between cumulative risk index, family functioning, family regularity, and internalizing and externalizing problems for boys $(\mathrm{N}=1548)$

\begin{tabular}{|c|c|c|c|c|c|}
\hline & \multicolumn{5}{|c|}{ Estimate coefficients ( $95 \%$ confidence intervals) } \\
\hline & Model 1 & Model 2 & Model 3 & Model 4 & Model 5 \\
\hline \multicolumn{6}{|c|}{ Outcome: Int. prob } \\
\hline Intercept & $\begin{array}{l}-0.32 \\
(-0.48,-0.17)^{* * *}\end{array}$ & $\begin{array}{l}-0.32 \\
\quad(-0.48,-0.17)^{* * * *}\end{array}$ & $\begin{array}{l}-0.32 \\
\quad(-0.48,-0.17)^{* * * *}\end{array}$ & $\begin{array}{l}-0.32 \\
\quad(-0.47,-0.16)^{* * *}\end{array}$ & $\begin{array}{l}-0.32 \\
(-0.47,-0.16)^{* * *}\end{array}$ \\
\hline Child age & $0.03(-0.12,0.18)$ & $0.04(-0.11,0.18)$ & $0.04(-0.12,0.18)$ & $0.04(-0.11,0.19)$ & $0.03(-0.12,0.19)$ \\
\hline $\begin{array}{l}\text { Child eth- } \\
\text { nicity }\end{array}$ & $0.18(0.06,0.30)^{* *}$ & $0.18(0.06,0.30)^{* *}$ & $0.18(0.06,0.30)^{* *}$ & $0.18(0.06,0.30)^{* *}$ & $0.18(0.06,0.30)^{* *}$ \\
\hline CR index & $0.03(0.02,0.05)^{* * *}$ & $0.03(0.02,0.05)^{* * *}$ & $0.03(0.02,0.05)^{* * *}$ & $0.03(0.02,0.05)^{* * *}$ & $0.03(0.02,0.05)^{* * *}$ \\
\hline Family func & & $0.03(-0.10,0.16)$ & $0.03(-0.10,0.15)$ & & \\
\hline Family reg & & & & $-0.01(-0.07,0.05)$ & $-0.01(-0.07,0.05)$ \\
\hline $\begin{array}{l}\text { CR index } \\
* \text { Family } \\
\text { func }\end{array}$ & & & $0.00(-0.03,0.03)$ & & \\
\hline $\begin{array}{l}\text { CR index } \\
\text { * Family } \\
\text { reg }\end{array}$ & & & & & $-0.00(-0.02,0.02)$ \\
\hline$R$-squared & 0.02 & 0.02 & 0.02 & 0.02 & 0.02 \\
\hline \multicolumn{6}{|c|}{ Outcome: Ext. prob } \\
\hline Intercept & $0.16(-0.03,0.34)$ & $0.16(-0.02,0.35)$ & $0.17(-0.01,0.35)$ & $0.18(-0.01,0.36)$ & $0.18(-0.01,0.36)$ \\
\hline Child age & $0.01(-0.14,0.17)$ & $0.01(-0.15,0.16)$ & $0.01(-0.15,0.16)$ & $0.02(-0.14,0.18)$ & $0.02(-0.14,0.18)$ \\
\hline $\begin{array}{l}\text { Child eth- } \\
\text { nicity }\end{array}$ & $0.00(-0.14,0.15)$ & $-0.00(-0.15,0.14)$ & $-0.00(-0.14,0.14)$ & $-0.01(-0.15,0.13)$ & $-0.011(-0.15,0.13)$ \\
\hline CR index & $0.04(0.02,0.06)^{* * *}$ & $0.03(0.01,0.05)^{* *}$ & $0.04(0.02,0.06)^{* *}$ & $0.04(0.02,0.06)^{* * *}$ & $0.04(0.02,0.06)^{* * *}$ \\
\hline Family func & & $-0.18(-0.34,-0.02)^{*}$ & $-0.20(-0.35,-0.04)^{*}$ & & \\
\hline Family reg & & & & $-0.06(-0.13,0.01)$ & $-0.06(-0.12,0.01)$ \\
\hline $\begin{array}{l}\text { CR index } \\
* \text { Family } \\
\text { func }\end{array}$ & & & $0.03(-0.02,0.07)$ & & \\
\hline $\begin{array}{l}\text { CR index } \\
\text { * Family } \\
\text { reg }\end{array}$ & & & & & $-0.01(-0.03,0.02)$ \\
\hline$R$-squared & 0.01 & 0.02 & 0.02 & 0.01 & 0.01 \\
\hline
\end{tabular}

Boldface coefficients indicate significance at $p<.05$ level after Benjamini-Hochberg correction for multiple testing. Internalizing and externalizing problems were standardized. Independent variables were mean centered

Note. Int. prob. internalizing problems, Ext. prob. externalizing problems, CR cumulative risk, Family func. family functioning, Family reg. family regularity

${ }^{*} p<.05 ; * * p<.01 ; * * * p<.001$

Table 3, Model 6) of the whole sample revealed that the association between $\mathrm{CR}$ and internalizing problems did not differ significantly between boys and girls $(\beta=0.02$, $p=0.209$ ).

In Model 2, we added family functioning to the equation. Table 2 reveals that, accounting for child age, ethnicity, and $\mathrm{CR}$, the association between family functioning and boys' internalizing problems was not significant $(\beta=0.03, p=0.644)$. The adjusted $R^{2}$ for Model 2 was 0.02 for boys $\left(\Delta R^{2}=0.00\right)$. As shown in Table 3, family functioning was also not associated with girls' internalizing problems $(\beta=-0.12, p=0.075)$. The adjusted $R^{2}$ for Model 2 was 0.04 for girls $\left(\Delta R^{2}=0.00\right)$. Supplementary analyses (Online Resource Table 3, Model 7) revealed that the association between family functioning and internalizing problems did not differ significantly between boys and girls $(\beta=-0.16, p=0.088)$. Thus, based on the three criteria for the compensatory model of resilience, our results revealed that family functioning did not compensate for the negative relationship between CR and children's internalizing problems. 
Table 3 Associations between cumulative risk index, family functioning, family regularity, and internalizing and externalizing problems for girls $(\mathrm{N}=1611)$

\begin{tabular}{|c|c|c|c|c|c|}
\hline & \multicolumn{5}{|c|}{ Estimate coefficients ( $95 \%$ confidence intervals) } \\
\hline & Model 1 & Model 2 & Model 3 & Model 4 & Model 5 \\
\hline \multicolumn{6}{|l|}{ Outcome: Int. prob } \\
\hline Intercept & $\begin{array}{l}-0.27 \\
\quad(-0.43,-0.11)^{* *}\end{array}$ & $\begin{array}{l}-0.25 \\
\quad(-0.41,-0.09)^{* *}\end{array}$ & $\begin{array}{l}-0.25 \\
\quad(-0.41,-0.09)^{* *}\end{array}$ & $\begin{array}{l}-0.26 \\
\quad(-0.42,-0.11)^{* *}\end{array}$ & $\begin{array}{l}-0.26 \\
\quad(-0.42,-0.10)^{* *}\end{array}$ \\
\hline Child age & $0.02(-0.16,0.19)$ & $0.02(-0.15,0.12)$ & $0.02(-0.15,0.20)$ & $0.02(-0.16,0.19)$ & $0.02(-0.15,0.19)$ \\
\hline Child ethnicity & $0.28(0.16,0.40)^{* * *}$ & $0.27(0.14,0.39)^{* * *}$ & $0.27(0.14,0.39) * * *$ & $0.28(0.15,0.40)^{* * *}$ & $0.28(0.15,0.40)^{* * *}$ \\
\hline CR index & $0.04(0.03,0.06)^{* * *}$ & $0.04(0.02,0.06)^{* * *}$ & $0.04(0.02,0.06)^{* * *}$ & $0.04(0.03,0.06)^{* * *}$ & $0.05(0.03,0.06)^{* * *}$ \\
\hline Family func & & $-0.12(-0.26,0.01)$ & $-0.12(-0.26,0.01)$ & & \\
\hline Family reg & & & & $-0.02(-0.09,0.04)$ & $-0.03(-0.09,0.04)$ \\
\hline $\begin{array}{l}\text { CR index * Family } \\
\text { func }\end{array}$ & & & $-0.00(-0.04,0.04)$ & & \\
\hline $\begin{array}{l}\text { CR index * Family } \\
\text { reg }\end{array}$ & & & & & $0.01(-0.01,0.03)$ \\
\hline$R$-squared & 0.04 & 0.04 & 0.04 & 0.04 & 0.04 \\
\hline \multicolumn{6}{|l|}{ Outcome: Ext. prob } \\
\hline Intercept & $\begin{array}{l}-0.19 \\
\quad(-0.32,-0.07)^{* *}\end{array}$ & $\begin{array}{l}-0.18 \\
\quad(-0.31,-0.05)^{* *}\end{array}$ & $\begin{array}{l}-0.18 \\
\quad(-0.31,-0.05)^{* *}\end{array}$ & $\begin{array}{l}-0.19 \\
\quad(-0.32,-0.07)^{* *}\end{array}$ & $\begin{array}{l}-0.19 \\
\quad(-0.32,-0.07)^{* *}\end{array}$ \\
\hline Child age & $0.04(-0.12,0.19)$ & $0.04(-0.11,0.19)$ & $0.04(-0.11,0.19)$ & $0.04(-0.12,0.19)$ & $0.03(-0.12,0.19)$ \\
\hline Child ethnicity & $0.02(-0.07,0.12)$ & $0.02(-0.08,0.11)$ & $0.02(-0.08,0.11)$ & $0.02(-0.07,0.12)$ & $0.03(-0.07,0.12)$ \\
\hline CR index & $0.01(-0.00,0.03)$ & $0.01(-0.00,0.03)$ & $0.01(-0.00,0.03)$ & $0.01(-0.00,0.03)$ & $0.01(-0.00,0.03)$ \\
\hline Family func & & $-0.07(-0.18,0.03)$ & $-0.07(-0.18,0.03)$ & & \\
\hline Family reg & & & & $0.01(-0.04,0.05)$ & $0.01(-0.04,0.06)$ \\
\hline $\begin{array}{l}\text { CR index * Family } \\
\text { func }\end{array}$ & & & $0.01(-0.03,0.04)$ & & \\
\hline $\begin{array}{l}\mathrm{CR} \text { index * Family } \\
\text { reg }\end{array}$ & & & & & $-0.00(-0.02,0.01)$ \\
\hline$R$-squared & 0.00 & 0.00 & 0.00 & 0.00 & 0.00 \\
\hline
\end{tabular}

Boldface coefficients indicate significance at $p<.05$ level after Benjamini-Hochberg correction for multiple testing. Internalizing and externalizing problems were standardized. Independent variables were mean centered

Note. Int. prob. internalizing problems, Ext. prob. externalizing problems, CR cumulative risk, Family func. family functioning, Family reg. family regularity

${ }^{*} p<.05 ; * * p<.01 ; * * * p<.001$

Model 3 builds on Model 2 and includes the interaction term between CR and family functioning. Findings for boys (Table 2) indicate that family functioning did not significantly moderate the association between $\mathrm{CR}$ and internalizing problems $(\beta=0.00, p=0.956)$. In line with the findings for boys, Table 3 revealed that family functioning also did not significantly moderate the association between CR and girls' internalizing problems $(\beta=0.00, p=0.956)$. Supplementary analyses (Online Resource Table 3, Model 8) show that the coefficient for the interaction effect between $\mathrm{CR}$ and family functioning did not significantly differ between boys and girls $(\beta=0.00, p=0.927)$. Therefore, our findings revealed that family functioning did not play a buffering role in the association between CR and children's internalizing problems.
Model 4 builds on Model 1, but here we added family regularity to the model. Table 2 shows that, accounting for child age, ethnicity, and CR, the association between family regularity and boys' internalizing problems was not significant ( $\beta=-0.01, p=0.650$ ). The adjusted $R^{2}$ for Model 4 for boys was $0.02\left(\Delta R^{2}=0.00\right)$. Findings for girls in Table 3 show a similar pattern: family regularity was not significantly associated with girls' internalizing problems $(\beta=-0.02$, $p=0.459$ ). The adjusted $R^{2}$ for Model 3 for girls was 0.04 for girls $\left(\Delta R^{2}=0.00\right)$. Supplementary analysis (Online Resource Table 3, Model 9) revealed that associations between family regularity and internalizing problems did not significantly differ between boys and girls $(\beta=-0.01, p=0.748)$. Based on the three criteria for the compensatory model of resilience, our findings showed that family regularity did not 
compensate for the negative relationship between CR and internalizing problem.

Model 5 builds on Model 4 and adds the interaction term between $\mathrm{CR}$ and family regularity. Findings for boys (Table 2) show that family regularity did not significantly moderate the association between $\mathrm{CR}$ and internalizing problems $(\beta=-0.00, p=0.644)$. For girls (Table 3$)$, similar findings were found: the interaction between CR and family regularity was not significantly related to girls' internalizing problems $(\beta=0.01, p=0.298)$. Supplementary analyses (Online Resource Table 3, Model 10) revealed that that the coefficient for the interaction effect between CR and family regularity did not significantly differ between boys and girls $(\beta=0.02, p=0.286)$.

In sum, our results showed that $\mathrm{CR}$ was associated with internalizing problems for both girls and boys. As neither family functioning nor family regularity was associated with internalizing problems, we did not find support for a compensatory or a buffering role of family functioning and family regularity in the associations between CR and children's internalizing problems.

\section{Associations Between CR, Family Functioning, Family Regularity, and Children's Externalizing Problems}

Controlling for child age and ethnicity, Model 1 in Table 2 shows that CR was positively associated with boys' externalizing problems $(\beta=0.04, p<0.001)$. The pooled $R^{2}$ for Model 1 was 0.01 for boys. In contrast, findings for girls (Model 2 in Table 3) show that CR was not significantly associated with girls' externalizing problems $(\beta=0.01$, $p=0.060$ ). The pooled $R^{2}$ for Model 1 was 0.00 for girls. Despite these different patterns for boys and girls, supplementary analysis (Online Resource Table 3, Model 6) shows that the association between CR and children's externalizing behavior did not differ significantly between boys and girls $(\beta=-0.02, p=0.055)$.

In Model 2, family functioning was added. Findings for boys (Table 2 ) show that family functioning was negatively associated with boys' externalizing problems $(\beta=-0.18$, $p=0.025$ ); the healthier the family functioning, the fewer externalizing problems boys reported. However, this relationship was no longer significant at the $p<0.05$ level after performing the false rate discovery correction using the Benjamini-Hochberg method. Consequently, based on Zimmerman and Fergus' (2005) view of the compensatory model, family functioning did not significantly counteract the relationship between CR and boys' externalizing problems. Moreover, with regard to Buckley et al.'s (2020) criteria, family functioning barely explained unique variance in externalizing problems in addition to the variance explained by $\mathrm{CR}$, as the adjusted $R^{2}$ for Model 2 was
0.02 for boys $\left(\Delta R^{2}=0.00\right)$. The findings for girls (Model 2 , Table 3) also showed that family functioning was not significantly associated with girls' externalizing problems $(\beta=-0.07, p=0.183)$. The adjusted $R^{2}$ for Model 2 was 0.00 for girls $\left(\Delta R^{2}=0.00\right)$. Supplementary analyses (Online Resource Table 3, Model 7) revealed that the association between family functioning and children's externalizing problems did not differ significantly between boys and girls $(\beta=0.11, p=0.266)$. Therefore, we did not find support for family functioning compensating for the negative association between CR and children's externalizing problems. Model 3 builds on Model 2 by adding the interaction term between CR and family functioning. Consistent with the results for internalizing problems, family functioning did not significantly moderate the association between CR and boys' externalizing problems ( $\beta=0.03, p=0.239$ ). The same pattern was found for girls (Table 3): family functioning did not significantly moderate the association between $\mathrm{CR}$ and girls' externalizing problems $(\beta=0.01$, $p=0.702)$. In line with these findings, supplementary analyses (Online Resource Table 3, Model 8) revealed that the coefficient for the interaction term between CR and family functioning on children's externalizing problems did not differ between boys and girls $(\beta=-0.02, p=0.486)$. Therefore, our results showed that family functioning did not play a buffering role in the associations between $\mathrm{CR}$ and children's externalizing problems.

Model 4 builds on Model, but here we added family regularity. Table 2 shows that family regularity was not significantly associated with boys' externalizing problems $(\beta=-0.06, p=0.079)$. The adjusted $R^{2}$ for Model 4 was 0.01 for boys $\left(\Delta R^{2}=0.00\right)$. The same was found for girls (Table 3 ); family regularity was not significantly associated with girls' externalizing problems $(\beta=0.01$, $p=0.814$ ). The adjusted $R^{2}$ for Model 3 was 0.00 for girls $\left(\Delta R^{2}=0.00\right)$. Supplementary analysis (Online Resource Table 3, Model 9) shows that the association between family regularity and children's externalizing problems did not significantly differ between boys and girls $(\beta=0.06, p=0.126)$. Therefore, our findings revealed that family regularity did not meet the criteria for a compensatory role for children's externalizing problems.

Finally, Model 5 builds on Model 4 by adding the interaction term between CR and family regularity. Table 2 shows that family regularity did not moderate the association between $\mathrm{CR}$ and boys' externalizing problems $(\beta=-0.01, p=0.607)$. Similarly, a non-significant interaction term was found for girls (Table $3 ; \beta=0.00, p=0.660$ ). Supplementary analyses (Online Resource Table 3, Model 10) showed that the coefficient for the interaction term between CR and family regularity on children's externalizing problems did not significantly differ between boys 
and girls $(\beta=0.00, p=0.885)$. Therefore, our findings showed that family regularity did not play a buffering role in the relations between CR and children's externalizing problems.

\section{Sensitivity Analyses}

We conducted sensitivity analyses to investigate to what extent the associations between CR, family functioning, family regularity, and internalizing and externalizing problems are comparable among non-Dutch participants. Based on earlier research (Cortes Hidalgo et al., 2020) and the Statistics Netherlands (2004) we created the following three non-Dutch subgroups. The non-Dutch Western group $(n=297)$ included participants who came from European, Indonesian, Oceania, Western American, and Western Asian countries. The Caribbean ethnic group $(n=217)$ included participants who came from Suriname and the Dutch Antilles. The Turkish/Moroccan ethnic group $(n=186)$ included participants who came from Turkey and Morocco. Our sample also includes participants who belong to the following four groups: participants who came from African $(n=104)$, non-Western Asian $(n=59)$, and non-Western American $(n=49)$ countries. Given the small sample sizes and heterogeneity within the latter four subgroups, we did not include these in the sensitivity analyses. Although the levels of CR, family functioning, family regularity, and internalizing and externalizing problems differed between subgroups, the associations among these variables were not substantially different across the Dutch, non-Dutch Western, Caribbean, and Turkish/Moroccan subgroups and did not differ from the associations reported for the entire sample.

\section{Discussion}

Embedded within the framework of the bioecological theory, family systems theory, and the resilience approach, the present study analyzed whether family functioning and family regularity could compensate for and buffer against the deleterious effects of the accumulation of risks on early childhood internalizing and externalizing problems. Consistent with previous work, we found that a CR index encompassing risks in interpersonal, parental, contextual, life stress, and direct victimization domains was positively associated with internalizing and externalizing problems in childhood (Carneiro et al., 2016; Kysar-Moon, 2021; Wallander et al., 2019). This provides support for the CR framework's core assumption that the quantity of accumulated risks can reliably predict child outcomes. In contrast to our expectations, family functioning or family regularity was not associated with children's problem behavior in our study. Similarly, neither family functioning nor family regularity buffered the associations between CR and internalizing or externalizing problems.

\section{Compensatory Model of Resilience}

The current study tested the compensatory role of family functioning on internalizing and externalizing problems accounting for CR. Contrary to our expectations, we did not find an association between family functioning and girls' or boys' internalizing or externalizing problems. As such, our findings were not consistent with studies that reported direct associations between (prenatal) family functioning and children's internalizing problems (Crawford et al., 2011; Kennedy et al., 2015; Velders et al., 2011), or those between family functioning and child anxiety and global functioning (Hughes et al., 2008), or those between family functioning and externalizing problems (Davies et al., 2004; Henderson et al., 2006).

We pose that the association between family functioning and child internalizing and externalizing problems found in previous studies might have been present because these studies were not able to control for important confounding variables, such as those captured by the CRs that this study was able to take into account. For example, one can think of stressful life events (such as a parental death, sickness in the family, problems within the family). Of note, the association may be particularly confounded by problems with marriage relation, ongoing conflicts between the child and family members, or conflicts between other family members, as these are related to both less healthy overall family functioning as well as higher levels of internalizing and externalizing problems. Not controlling for such events may have led to an overestimation of the association between family functioning and child internalizing and externalizing problems in previous studies.

An alternative reason for inconsistency in findings might be the presence or absence of single-source bias. Studies that found significant associations between family functioning and children's internalizing and externalizing problems used measures that were either both reported by caregivers (e.g., Crawford et al., 2011; Velders et al., 2011) or were both selfreported by children (e.g., Henderson et al., 2006; Kennedy et al., 2015). In the present study, we relied on mother-report of family functioning and child self-report on internalizing and externalizing problems. Therefore, we encourage future research to study to what extent a wide range of accumulated risk factors may confound the relationship between family functioning and child internalizing and externalizing problems using multiple informants.

We also tested the compensatory role of family regularity on child internalizing and externalizing problems in the 
context of CR. Contrary to our expectations, our results showed that neither criterion of the compensatory model was met for the associations between family regularity and internalizing and externalizing problems, when accounting for CR. These findings are inconsistent with studies wherein family routines were found to lower the risks for child and adolescent internalizing and externalizing symptoms (Elgar et al., 2013; Kliewer \& Kung, 1998; Loukas \& Prelow, 2004). Nonetheless, similar to our findings, Koblinsky et al. (2006) found that family routines were not associated with African American preschoolers' internalizing problems. They argued that regular family routines may not "help to reduce children's anxious, fearful, sad, and withdrawn behavior" and that "direct, one-on-one parental guidance that addresses children's feelings and worries ... may be necessary to lessen preschoolers' internalizing problems" (Koblinsky et al., 2006, p. 560). It is possible that family routines that are not centered around one-on-one parental guidance but rather around dynamics that are inclusive to all family members may not be beneficial for all children. Therefore, family regularity might only be important to children who are known to benefit from structure. For example, Stoppelbein et al. (2016) reported curvilinear associations between routines and internalizing and externalizing symptoms in children diagnosed with autism spectrum disorder, although they did not identify associations in typically developing children after controlling for parental adjustment problems. Thus, we recommend future studies to examine under what conditions family regularity is beneficial for children's adjustment in the context of CR.

The lack of association between family regularity and internalizing and externalizing problems in our study might also be explained by our operationalization of family regularity, which was defined as the frequency of regular family routines. Yet, it is unclear whether the frequency of regular family routines aligns with the quality of interactions during such routines. For example, family mealtimes and bedtime rituals that include supportive elements, such as support by others, well-regulated behaviors, appropriate role assignment, and emotional responsiveness (i.e., factors related to healthy family functioning) are related to more optimal child developmental outcomes (Fiese, 2007; Fiese \& Schwartz, 2008). Therefore, we encourage future researchers to investigate whether measures of family regularity that take into account both the frequency as well as the quality of family meal and bedtime routines do find support for its compensatory or buffering role.

\section{Risk-Protective Factor Model of Resilience}

Our study showed that family functioning and family regularity did not buffer the associations between $\mathrm{CR}$ and internalizing or externalizing problems. Although these findings were not in line with our expectations, they are consistent with the findings of Sheidow et al. (2014). The authors did not find support for the moderating role of family functioning between exposure to stress and adolescent boys' internalizing problems. The fact that we did not find evidence for the moderating or buffering roles of family functioning and family regularity on the detrimental influence of CRs does not necessarily imply that mesolevel factors in general are not worthy of investigation as potential buffers or moderators. It is plausible that other family-level resources, such as close relationships, belonging, skilled family management, hope and optimism, sense of family meaning and purpose, and positive views of the family could buffer the relations between CR and child internalizing and externalizing problems (Masten \& Motti-Stefanidi, 2020). Furthermore, scholars have shown that shared emotions derived from family and parent-child interactions are of importance and can have buffering effects as well. For example, the findings by Mäntymaa et al. (2015) outlined the buffering role of shared pleasure (i.e., sharing positive affect in synchrony) in parent-infant interactions in the associations between parental psychopathology and infant internalizing and externalizing problems.

Moreover, in the resilience framework, Zimmerman (2013) indicated an additional source of resilience besides resources, namely, assets. Assets refer to factors residing within the individual, for example, self-efficacy, self-esteem, competence, and coping skills (Fergus \& Zimmerman, 2005; Zimmerman, 2013). It could be that assets play a crucial role in mitigating the influence of CR on young children's internalizing and externalizing problems. For example, the findings by De Maat et al. (2021) underscored the buffering role of child temperament in the associations between $\mathrm{CR}$ and teacher-reported 7-year-old-children's externalizing problems, and the buffering role of child executive functioning in the associations between CR and teacher-reported 7-year-old children's internalizing problems. Therefore, we recommend future studies to explore whether not only additional mesolevel resources, and the shared emotions derived from them, -but also assets- are essential for buffering the associations between CR and preschool-age children's internalizing and externalizing problems.

\section{Strengths, Limitations, and Future Study Recommendations}

The novelty of our paper lies in our resilience models testing compensatory and buffering roles of mesolevel family factors in early childhood across a large population-based sample. Measures were assessed by multiple informants (i.e., mothers, fathers, and children), which increased the reliability of our results, as well as reduced single source bias. Compared to previous CR indices (e.g., Ettekal et al., 2019; Wallander et al., 2019), our CR index was relatively large in scope as the index included 48 risk items assessed in the time period between birth and 5 years of age, and spanned across various 
risk domains. The CR index included assessments of both maternal and paternal demographic factors, psychopathology, and harsh parenting and therefore overcame a limitation of previous studies where the roles of paternal mental health and parenting practices were overlooked in early childhood development (e.g., Ettekal et al., 2019; Wallander et al., 2019). Importantly, risks on parental mental health and parenting practices tapped into individual characteristics, while our operationalization of family functioning tapped into processes and dynamics at the family level.

Besides the strengths of the present study, important methodological limitations must be addressed. First, we would like to note three shortcomings of CR indices that are based on dichotomous items: (1) thresholds used to assign (presence versus absence of) risks to items may be arbitrary, (2) information on intensity and chronicity of risks may be lost during the process of dichotomization, and (3) items within a CR index could be (in)directly related to one another (e.g., household income, parental psychopathology, and harsh parenting). In the present paper, we relied on theoretical and/ or statistical motivation to assign risks to items. Moreover, Ettekal et al. (2019) examined multiple approaches to studying CRs in predicting externalizing problems in early childhood. Among other approaches, they compared the predictive ability of a CR index based on dichotomous risk items with a CR index based on proportion scores, which maintained the varying degree of severity of continuous items (Ettekal et al., 2019). Their findings revealed that the differences in effect sizes across the two CR approaches were negligible. With respect to risk items that were measured at multiple time points, such as household income and parental education, we were able to consider the chronicity of risks on these items by computing a new item which reflects upon the presence of risk at least once across multiple measurements. Taking into consideration the shortcomings of our variable-centered approach, we recommend future researchers to investigate the relative weight of individual risk items and to consider alternative mediating and moderating pathways through which risks and promotive factors can predict child internalizing and externalizing problems. Second, our study population is mostly representative of Dutch children with relatively low scores on internalizing and externalizing problems, living in two-parent families, who have reported low levels of CRs, relatively healthy family functioning, and relatively higher levels of family regularity. The weak correlations between our study variables likely explain the relatively small explained variances $\left(R^{2}\right)$ of our models. In addition, the relatively small variance in CRs, family functioning, and family regularity could have contributed to the lack of buffering effects by family functioning and family regularity in the associations between CRs and internalizing and externalizing problems. We encourage researchers to replicate our study in vulnerable populations using complementary CR approaches (e.g., summarized by Ettekal et al., 2019). Third, we are unable to infer causality based on our findings. We recommend future research to examine the temporal ordering of CRs, family functioning, and regularity with child development, and to disentangle within-family and between-family effects, for instance, in random intercept cross-lagged panel models.

We would like to make an additional recommendation for future studies. Family functioning was assessed via maternal self-report on the General Functioning scale of the McMaster Family Assessment Device. We recommend for smallscale studies to objectively assess family functioning by including an observational element of family functioning, such as the McMaster Interaction Coding System, which could be applied on video-taped family interactions during mealtimes (Dickstein et al., 1994). Naturalistic observation of family functioning during mealtimes could provide insight into the nature of triadic interactions between mother, father, and child and would complementarily capture the quality of family regularity with respect to family mealtimes.

In light of our findings, we recommend professionals and policy makers to pay particular attention to young children who have accumulated risks early on in their lives. We recommend clinicians and professionals to consider early life CRs when planning treatment and interventions for problem behaviors, for example, by screening for accumulated risks. Moreover, our findings suggest that the use of a CR index may be beneficial for identifying children who are at higher risk for developing internalizing and externalizing problems in the early school years.

\section{Conclusions}

Within the frameworks of Bronfenbrenner's bioecological model, family systems theory, and models of resilience, the present study contributed to current knowledge on the role of mesolevel family factors in the associations between CR and internalizing and externalizing problems in early childhood. Although we found no support for a compensatory or protective role of family functioning or family regularity on children's internalizing or externalizing problems in the context of CRs, our findings show that children's levels of CRs are associated with internalizing and externalizing problems in early childhood. We recommend practitioners and researchers to screen for an accumulation of risks to identify children who may be at higher risk for developing behavior problems as well as to use CRs as a guide for planning prevention and intervention.

Supplementary Information The online version contains supplementary material available at https://doi.org/10.1007/s42844-022-00056-y.

Author Contribution S.H.: designed and executed the study, analyzed the data, and wrote the manuscript. N.L.: designed and executed the study, and collaborated in writing multiple versions of the manuscript. 
P.J.: designed and executed the study, and collaborated in writing multiple versions of the manuscript. I.S.: designed and executed the study, assisted in the data analyses, and collaborated in writing multiple versions of the manuscript. R.K.: designed and executed the study, and collaborated in writing multiple versions of the manuscript.

Funding The present study was supported by a grant from the Dutch Research Council (NWO MaGW VIDI; grant no. 452-17-005) to R.K. and by a grant from the European Research Council (ERC StG; grant no. 757210) to R.K. The general design of Generation R Study is made possible by financial support from the Erasmus MC University Medical Center, Rotterdam, the Erasmus University Rotterdam, the Netherlands Organization for Health Research and Development (ZonMw), the Dutch Research Council (NWO), the Ministry of Health, Welfare and Sport and the Ministry of Youth and Families.

Data Availability Data can be obtained upon request. Requests should be directed toward the management team of the Generation R Study (secretariaat.genr@erasmusmc.nl),which has a protocol of approving data requests. Because of restrictions based on privacy regulations and informed consent of participants, data cannot be made freely available in a public repository.

Code Availability Code used for data analyses using R version 4.1 .2 can be obtained from the corresponding author upon request.

\section{Declarations}

Ethics Approval The study is in accordance with the 1964 Declaration of Helsinki of the World Medical Association and has received approval from the Medical Ethical Committee of the Erasmus University Medical Center in Rotterdam.

Consent to Participate Parents provided written informed consent for their own participation as well as on behalf of their child.

Consent for Publication Not applicable.

Conflict of Interest The authors declare no competing interests.

Open Access This article is licensed under a Creative Commons Attribution 4.0 International License, which permits use, sharing, adaptation, distribution and reproduction in any medium or format, as long as you give appropriate credit to the original author(s) and the source, provide a link to the Creative Commons licence, and indicate if changes were made. The images or other third party material in this article are included in the article's Creative Commons licence, unless indicated otherwise in a credit line to the material. If material is not included in the article's Creative Commons licence and your intended use is not permitted by statutory regulation or exceeds the permitted use, you will need to obtain permission directly from the copyright holder. To view a copy of this licence, visit http://creativecommons.org/licenses/by/4.0/.

\section{References}

Ablow, J. C., Measelle, J. R., \& the MacArthur Working Group on Outcome Assessment, (2003). Manual for the Berkeley Puppet Interview: Symptomatology, social, and academic modules (BPI 1.0). Pittsburgh, PA: University of Pittsburgh.

Ackerman, B. P., Izard, C. E., Schoff, K., Youngstrom, E. A., \& Kogos, J. (1999). Contextual risk, caregiver emotionality, and the problem behaviors of six- and seven-year-old children from economically disadvantaged families. Child Development, 70(6), 1415-1427. https://doi.org/10.1111/1467-8624.00103

Appleyard, K., Egeland, B., Van Dulmen, M. H. M., \& Alan Sroufe, L. (2005). When more is not better: The role of cumulative risk in child behavior outcomes. Journal of Child Psychology and Psychiatry, 46(3), 235-245. https://doi.org/10.1111/j.1469-7610. 2004.00351.x

Bao, J., Gudmunson, C. G., Greder, K., \& Smith, S. R. (2019). The impact of family rituals and maternal depressive symptoms on child externalizing behaviors: An urban-rural comparison. Child \& Youth Care Forum, 48(6), 935-953. https://doi.org/10.1007/ s10566-019-09512-w

Benjamini, Y., \& Hochberg, Y. (1995). Controlling the false discovery rate: A practical and powerful approach to multiple testing. Journal of the Royal Statistical Society: Series B (methodological), 57(1), 289-300.

Bronfenbrenner, U., \& Morris, P. A. (1998). The ecology of developmental processes. In Handbook of child psychology: Theoretical models of human development (Vol. 1, 5th ed., pp. 993-1028). Hoboken: John Wiley \& Sons Inc.

Buckley, L., \& Chapman, R. L. (2020). Resiliency in adolescence: Cumulative risk and promotive factors explain violence and transportation risk behaviors. Youth \& Society, 52(3), 311-331. https:// doi.org/10.1177/0044118X17753814

Byles, J., Byrne, C., Boyle, M. H., \& Offord, D. R. (1988). Ontario Child Health Study: Reliability and validity of the general functioning subscale of the McMaster Family Assessment Device. Family Process, 27(1), 97-104. https://doi.org/10.1111/j.15455300.1988.00097.x

Caldwell, B. M., \& Bradley, R. H. (1984). Home observation for measurement of the environment. AR, University of Arkansas.

Carneiro, A., Dias, P., \& Soares, I. (2016). Risk factors for internalizing and externalizing problems in the preschool years: Systematic literature review based on the Child Behavior Checklist 11/2-5. Journal of Child and Family Studies, 25, 2941-2953. https://doi. org/10.1007/s10826-016-0456-z

Chad-Friedman, E., Botdorf, M., Riggins, T., \& Dougherty, L. R. (2020). Early childhood cumulative risk is associated with decreased global brain measures, cortical thickness, and cognitive functioning in school-age children. Developmental Psychobiology, 63(2), 192-205. https://doi.org/10.1002/dev.21956

Chang, H., Shelleby, E. C., Cheong, J., \& Shaw, D. S. (2012). Cumulative risk, negative emotionality, and emotion regulation as predictors of social competence in transition to school: A mediated moderation model. Social Development, 21(4), 780-800. https:// doi.org/10.1111/j.1467-9507.2011.00648.x

Cortes Hidalgo, A. P., Neumann, A., Bakermans-Kranenburg, M. J., Jaddoe, V. W. V., Rijlaarsdam, J., Verhulst, F. C., White, T., van IJzendoorn, M. H., \& Tiemeier, H. (2020). Prenatal Maternal Stress and Child IQ. Child Development, 91(2), 347-365. https:// doi.org/10.1111/cdev.13177

Cox, M. J., \& Paley, B. (1997). Families as systems. Annual Review of Psychology, 48(1), 243-267. https://doi.org/10.1146/annurev. psych.48.1.243

Crawford, N. A., Schrock, M., \& Woodruff-Borden, J. (2011). Child internalizing symptoms: Contributions of child temperament, maternal negative affect, and family functioning. Child Psychiatry and Human Development, 42(1), 53-64. https://doi.org/10.1007/ s10578-010-0202-5

Davies, P. T., Cummings, E. M., \& Winter, M. A. (2004). Pathways between profiles of family functioning, child security in the interparental subsystems, and child psychological problems. Development and Psychopathology, 16(3), 525-550. https://doi.org/10. 1017/s0954579404004651

De Maat, D. A., Schuurmans, I. K., Jongerling, J., Metcalf, S. A., Lucassen, N., Franken, I. H. A., Prinzie, P., \& Jansen, P. W. (2021). 
Early life stress and behavior problems in early childhood: Investigating the contributions of child temperament and executive functions to resilience. Child Development, 93(1), e1-e16. https://doi. org/10.1111/cdev.13663

Derogatis, L. R., \& Melisaratos, N. (1983). The Brief Symptom Inventory: An introductory report. Psychological Medicine, 13(3), 595605. https://doi.org/10.1017/S0033291700048017

Dickstein, S., Hayden, L. C., Schiller, M., Seifer, R., \& San Antonio, W. (1994). The family mealtime interaction coding system. Unpublished coding manual.

Egger, H. L., \& Angold, A. (2006). Common emotional and behavioral disorders in preschool children: Presentation, nosology, and epidemiology. Journal of Child Psychology and Psychiatry, 47(3-4), 313-337. https://doi.org/10.1111/j.1469-7610.2006.01618.x

Elgar, F. J., Craig, W., \& Trites, S. J. (2013). Family dinners, communication, and mental health in Canadian adolescents. Journal of Adolescent Health, 52(4), 433-438. https://doi.org/10.1016/j. jadohealth.2012.07.012

Epstein, N. B., Ryan, C. E., Bishop, D. S., Miller, I. W., \& Keitner, G. I. (2003). The McMaster Model: A view of healthy family functioning. In F. Walsh (Ed.), Normal family processes: Growing diversity and complexity (3rd ed., pp. 581-607). Guilford Press.

Eriksen, H.-L.F., Hvidtfeldt, C., \& Lilleør, H. B. (2017). Family disruption and social, emotional and behavioral functioning in middle childhood. Journal of Child and Family Studies, 26(4), 10771089. https://doi.org/10.1007/s10826-016-0631-2

Ettekal, I., Eiden, R., Nickerson, A., \& Schuetze, P. (2019). Comparing alternative methods of measuring cumulative risk based on multiple risk indicators: Are there differential effects on children's externalizing problems? PLoS ONE, 14(7), e0219134. https://doi. org/10.1371/journal.pone.0219134

Evans, G. W., Li, D., \& Whipple, S. S. (2013). Cumulative risk and child development. Psychological Bulletin, 139(6), 1342-1396. https://doi.org/10.1037/a0031808

Fergus, S., \& Zimmerman, M. A. (2005). Adolescent resilience: A framework for understanding healthy development in the face of risk. Annual Review of Public Health, 26(1), 399-419. https://doi. org/10.1146/annurev.publhealth.26.021304.144357

Fiese, B. H. (1992). Dimensions of family rituals across two generations: Relation to adolescent identity. Family Process, 31(2), 151162. https://doi.org/10.1111/j.1545-5300.1992.00151.x

Fiese, B. H. (2007). Routines and rituals: Opportunities for participation in family health. OTJR: Occupation, Participation and Health, 27(suppl.), 41S-49S, https://doi.org/10.1177/1539449207 $0270 \mathrm{~S} 106$

Fiese, B. H., \& Schwartz, M. (2008). Reclaiming the family table: Mealtimes and child health and wellbeing. Society for Research in Child Development Social Policy Report, 22(4), 1-20. https:// doi.org/10.1002/j.2379-3988.2008.tb00057.x

Flink, I. J., Jansen, P. W., Beirens, T. M. J., Tiemeier, H., \& van IJzendoorn M. H., Jaddoe, V. W. V., Hofman, A., \& Raat, H. (2012). Differences in problem behaviour among ethnic minority and majority preschoolers in the Netherlands and the role of family functioning and parenting factors as mediators: The Generation R Study. BMC Public Health, 12, 1092. https://doi.org/10.1186/ 1471-2458-12-1092

Freed, R. D., Tomson, M. C., Wang, C. H., Otto, M. W., HirshfeldBecker, D. R., Nierenberg, A. A., \& Henin, A. (2015). Family functioning in the context of parental bipolar disorder: Associations with offspring age, sex, and psychopathology. Journal of Family Psychology, 29(1), 108-118. https://doi.org/10.1037/ fam0000048

Fryers, T., \& Brugha, T. (2013). Childhood determinants of adult psychiatric disorder. Clinical Practice and Epidemiology in Mental Health, 9, 1-50. https://doi.org/10.2174/1745017901309010001
Garmezy, N., Masten, A. S., \& Tellegen, A. (1984). The study of stress and competence in children: A building block for developmental psychopathology. Child Development, 55(1), 97-111. https://doi. org/10.2307/1129837

Goodman, S. H., Rouse, M. H., Connell, A. M., Broth, M. R., Hall, C. M., \& Heyward, D. (2011). Maternal depression and child psychopathology: A meta-analytic review. Clinical Child and Family Psychology Review, 14(1), 1-27. https://doi.org/10.1007/ s10567-010-0080-1

Hammarberg, A., \& Hagekull, B. (2006). Changes in externalizing and internalizing behaviours over a school-year period: Differences between 6-year-old boys and girls. Infant and Child Development, 15(2), 123-137. https://doi.org/10.1002/icd.444

Hatch, S. L., \& Dohrenwend, B. P. (2007). Distribution of traumatic and other stressful life events by race/ethnicity, sex, SES and age: A review of the research. American Journal of Community Psychology, 40(3-4), 313-332. https://doi.org/10.1007/ s10464-007-9134-z

Henderson, C. E., Dakof, G. A., Schwartz, S. J., \& Liddle, H. A. (2006). Family functioning, self-concept, and severity of adolescent externalizing problems. Journal of Child and Family Studies, 15, 721-731. https://doi.org/10.1007/s10826-006-9045-x

Holmes, T. H., \& Rahe, R. H. (1967). The social readjustment rating scale. Journal of Psychosomatic Research, 11(2), 213-218. https://doi.org/10.1016/0022-3999(67)90010-4

Houtepen, L. C., Heron, J., Suderman, M. J., Tilling, K., \& Howe, L. D. (2018). Adverse childhood experiences in the children of the Avon Longitudinal Study of Parents and Children (ALSPAC). Welcome Open Research, 3, 116. https://doi.org/10.12688/wellc omeopenres.14716.1

Hughes, A. A., Hedtke, K. A., \& Kendall, P. C. (2008). Family functioning in families of children with anxiety disorders. Journal of Family Psychology, 22(2), 325-328. https://doi.org/10.1037/ 0893-3200.22.2.325

Jensen, S. K. G., Dickie, E. W., Schwartz, D. H., Evans, J., Dumontheil, I., Paus, T., \& Barker, E. D. (2015). Effect of early adversity and childhood internalizing symptoms on brain structure in young men. JAMA Pediatrics, 169(10), 938-946. https:// doi.org/10.1001/jamapediatrics.2015.1486

Kalisch, R., Baker, D. G., Basten, U., Boks, M. P., Bonanno, G. A., Brummelman, E., Chmitorz, A., Fernàndez, G., Fiebach, C. J., Galatzer-Levy, I., Geuze, E., Groppa, S., Helmreich, I., Hendler, T., Hermans, E. J., Jovanovic, R., Kubiak, T., Lieb, K., Lutz, B., et al. (2017). The resilience framework as a strategy to combat stress-related disorders. Nature Human Behaviour, 1, 784-790. https://doi.org/10.1038/s41562-017-0200-8

Kane, P., \& Garber, J. (2004). The relations among depression in fathers, children's psychopathology, and father-child conflict: A meta-analysis. Clinical Psychology Review, 24(3), 339-360. https://doi.org/10.1016/j.cpr.2004.03.004

Kennedy, P., Rooney, R. M., Kane, R. T., Hassan, S., \& Nesa, M. (2015). The enhanced Aussie Optimism Positive Thinking Skills Program: The relation between internalizing symptoms and family functioning in children aged 9-11 years old. Frontiers in Psychology, 6, 504. https://doi.org/10.3389/fpsyg.2015.00504

Kim, S., \& Kochanska, G. (2015). Mothers' power assertion; children's negative, adversarial orientation; and future behavior problems in low-income families: Early maternal responsiveness as a moderator of the developmental cascade. Journal of Family Psychology, 29(1), 1-9. https://doi.org/10.1037/a0038430

Kingon, Y. S., \& O'Sullivan, A. L. (2001). The family as a protective asset in adolescent development. Journal of Holistic Nursing : Official Journal of the American Holistic Nurses' Association, 19(2), 102-121. https://doi.org/10.1177/089801010101900202 
Kiser, L. J. (2007). Protecting children from the dangers of urban poverty. Clinical Psychology Review, 27(2), 211-225. https://doi.org/ 10.1016/j.cpr.2006.07.004

Kliewer, W., \& Kung, E. (1998). Family moderators of the relation between hassles and behavior problems in inner-city youth. Journal of Clinical Psychology, 27(3), 278-292. https://doi.org/10. 1207/s15374424jccp2703_5

Koblinsky, S. A., Kuvalanka, K. A., \& Randolph, S. M. (2006). Social skills and behavior problems of urban, African American preschoolers: Role of parenting practices, family conflict, and maternal depression. American Journal of Orthopsychiatry, 76(4), 554-563. https://doi.org/10.1037/0002-9432.76.4.554

Kooijman, M. N., Kruithof, C. J., van Duijn, C. M., Duijts, L., Franco, O. H., van IJzendoorn, M. H., de Jongste, J. C., Klaver, C. C. W., van der Lugt, A., Mackenbach, J. P., Moll, H. A., Peeters, R. P., Raat, H., Rings, E. H. H. M., Rivadeneira, F., van der Schroeff, M. P., Steegers, A. P., Tiemeier, H., Uitterlinden, A. G., et al. (2016). The Generation R Study: design and cohort update 2017. European Journal of Epidemiology, 31(12), 1243-1264. https:// doi.org/10.1007/s10654-016-0224-9

Kysar-Moon, A. (2021). Adverse childhood experiences, family social capital, and externalizing behavior problems: An analysis across multiple ecological levels. Journal of Family Issues, Advance online publication, https://doi.org/10.1177/0192513X211042849

Lereya, S. T., Samara, M., \& Wolke, D. (2013). Parenting behavior and the risk of becoming a victim and a bully/victim: A meta-analysis study. Child Abuse \& Neglect, 37(12), 1091-1108. https://doi.org/ 10.1016/j.chiabu.2013.03.001

Loukas, A., \& Prelow, H. M. (2004). Externalizing and internalizing problems in low-income Latino early adolescents: Risk, resource, and protective factors. Journal of Early Adolescence, 24(3), 250 273. https://doi.org/10.1177/0272431604265675

Luthar, S. S. (2006). Resilience in development: A synthesis of research across five decades. In D. Cicchetti \& D. J. Cohen (Eds.), Developmental psychopathology: Risk, disorder, and adaptation (Vol. 3, 2nd ed., pp. 739-795). Hoboken, NJ, US: John Wiley \& Sons, Inc.

Maccoby, E. E. (1992). The role of parents in the socialization of children: An historical overview. Developmental Psychology, 28(6), 1006-1017. https://doi.org/10.1037/0012-1649.28.6.1006

Mäntymaa, M., Puura, K., Luoma, I., Latva, R., Salmelin, R. K., \& Tamminen, T. (2012). Predicting internalizing and externalizing problems at five years by child and parental factors in infancy and toddlerhood. Child Psychiatry and Human Development, 43(2), 153-170. https://doi.org/10.1007/s10578-011-0255-0

Mäntymaa, M., Puura, K., Luoma, I., Latva, R., Salmelin, R. K., \& Tamminen, T. (2015). Shared pleasure in early mother-infant interaction: Predicting lower levels of emotional and behavioral problems in the child and protecting against the influence of parental psychopathology. Infant Mental Health Journal, 36(2), 223-237. https://doi.org/10.1002/imhj.21505

March-Llanes, J., Marqués-Feixa, L., Mezquita, L., Fañanás, L., \& Moya-Higueras, J. (2017). Stressful life events during adolescence and risk for externalizing and internalizing psychopathology: A meta-analysis. European Child \& Adolescent Psychiatry, 26(12), 1409-1422. https://doi.org/10.1007/s00787-017-0996-9

Masten, A. S., \& Motti-Stefanidi, F. (2020). Multisystem resilience for children and youth in disaster: Reflections in the context of COVID-19. Adversity and Resilience Science, 1, 95-106. https:// doi.org/10.1007/s42844-020-00010-w

Mayes, S. D., Castagna, P. J., \& Waschbusch, D. A. (2020). Sex differences in externalizing and internalizing symptoms in ADHD, autism, and general population samples. Journal of Psychopathology and Behavioral Assessment, 42, 519-526. https://doi.org/10. 1007/s10862-020-09798-4
McFarland, M. J. (2017). Poverty and problem behaviors across the early life course: The role of sensitive period exposure. Population Research and Policy Review, 36(5), 739-760. https://doi.org/10. 1007/s11113-017-9442-4

McLaughlin, K. A., Hilt, L. M., \& Nolen-Hoeksema, S. (2007). Racial/ ethnic differences in McMaster Model: A view of healthy family functioning. In F. Walsh (Ed.), Normal family processes: Growing diversity and complexity (3rd ed., pp. 581-607). Guilford Press.

Measelle, J. R., Ablow, J. C., Cowan, P. A., \& Cowan, C. P. (1998). Assessing young children's views of their academic, social, and emotional lives: An evaluation of the self-perception scales of the Berkeley Puppet Interview. Child Development, 69(6), 15561576. https://doi.org/10.1111/j.1467-8624.1998.tb06177.x

Mesman, J., Bongers, I. K., \& Koot, H. M. (2001). Preschool developmental pathways to preadolescent internalizing and externalizing problems. Journal of Child Psychology and Psychiatry, Allied Disciplines, 42(5), 679-689. https://doi.org/10.1111/1469-7610. 00763

Miller, I. W., Epstein, N. B., Bishop, D. S., \& Keitner, G. I. (1985). The McMasters Family Assessment Device: Reliability and validity. Journal of Marital and Family Therapy, 11(4), 345-356. https:// doi.org/10.1111/j.1752-0606.1985.tb00028.x

Miller-Lewis, L. R., Searle, A. K., Sawyer, M. G., Baghurst, P. A., \& Hedley, D. (2013). Resource factors for mental health resilience in early childhood: An analysis with multiple methodologies. Child and Adolescent Psychiatry and Mental Health, 7, 6. https://doi. org/10.1186/1753-2000-7-6

Möller, E. L., Nikolić, M., Majdandžić, M., \& Bögels, S. M. (2016). Associations between maternal and paternal parenting behaviors, anxiety and its precursors in early childhood: A meta-analysis. Clinical Psychology Review, 45, 17-33. https://doi.org/10.1016/j. cpr.2016.03.002

Municipality of Rotterdam (2007). Rotterdammers Vooruit! : Rotterdamse Krachtwijken, Deel 1 [Rotterdammers Ahead: Rotterdam's Deprived Neighborhoods/Power Districts, Part 1]. In Dutch. Rotterdam: Municipality of Rotterdam. Available at: https://hdl. handle.net/21.12133/89F41649EA0E48B29719B2DECADF7953

National Scientific Council on the Developing Child. Excessive stress disrupts the architecture of the developing brain: Working paper no. 3. http://developingchild.harvard.edu/resources/wp3/. Updated 2014. Accessed December 12, 2021.

O'Donnell, J., \& Kingsley, M. (2020). The relationship between housing and children's socio-emotional and behavioral development in Australia. Children and Youth Services Review, 117. https://doi. org/10.1016/j.childyouth.2020.105290

Oldehinkel, A. J., \& Hartman, C. A. (2003). Vragenlijst ontwikkeld voor afname bij ouders van vroege adolescenten (12-14 jaar), in het kader van TRAILS, een onderzoek naar de gezondheid en ontwikkeling van jongeren op weg naar de volwassenheid. Rijksuniversiteit Groningen.

Oliva, A., Jiménez, J. M., \& Parra, Á. (2009). Protective effect of supportive family relationships and the influence of stressful life events on adolescent adjustment. Anxiety Stress and Coping, 22(2), 137-152. https://doi.org/10.1080/10615800802082296

Pinquart, M. (2017). Associations of parenting dimensions and styles with externalizing problems of children and adolescents: An updated meta-analysis. Developmental Psychology, 53(5), 873932. https://doi.org/10.1037/dev0000295

Rijlaarsdam, J., Stevens, G. W. J. M., van der Ende, J., Arends, L. R., Hofman, A., Jaddoe, V. W. V., Mackenbach, J. P., Verhulst, F. C., \& Tiemeier, H. (2012). A brief observational instrument for the assessment of infant home environment: development and psychometric testing. International Journal of Methods in Psychiatric Research, 21(3), 195-204. https://doi.org/10.1002/mpr.1361

Rijlaarsdam, J., Tiemeier, H., Ringoot, A. P., Ivanova, M. Y., Jaddoe, V. W. V., Verhulst, F. C., \& Roza, S. J. (2016). Early family 
regularity protects against later disruptive behavior. European Child and Adolescent Psychiatry, 25(7), 781-789. https://doi. org/10.1007/s00787-015-0797-y

Rijlaarsdam, J., van IJzendoorn, M. H., Verhulst, F. C., Jaddoe, V. W. V., Felix, J., Tiemeier, H., \& Bakermans-Kranenburg, M. J. (2017). Prenatal stress exposure, oxytocin receptor gene (OXTR) methylation and child autistic traits: The moderating role of OXTR rs53576 genotype. Autism Research, 10(3), 430-438. https://doi.org/10.1002/aur.168

Ringoot, A. P., Jansen, P. W., Steenweg-de Graaff, J., Measelle, J. R., van der Ende, J., Raat, H., Jaddoe, V. W. V., Albert, H., Verhulst, F. C., \& Tiemeier, H. (2013). Young children's self-reported emotional, behavioral, and peer problems: The Berkeley Puppet Interview. Psychological Assessment, 25(4), 1273-1285. https:// doi.org/10.1037/a0033976

Rollings, K. A., Wells, N. M., Evans, G. W., Bednarz, A., \& Yang, Y. (2017). Housing and neighborhood physical quality: Children's mental health and motivation. Journal of Environmental Psychology, 50, 17-23. https://doi.org/10.1016/j.jenvp.2017.01.004

Rutter, M. (1979). Protective factors in children's responses to stress and disadvantage. Annals of the Academy of Medicine, Singapore, $8(3), 324-338$

Rutter, M. (1985). Resilience in the face of adversity. Protective factors and resistance to psychiatric disorder. The British Journal of Psychiatry, 147, 598-611. https://doi.org/10.1192/bjp.147.6.598

Sameroff, A., Gutman, L. M., \& Peck, S. C. (2003). Adaptation among youth facing multiple risks: Prospective research findings. In Resilience and vulnerability: Adaptation in the context of childhood adversities (pp. 364-391). New York, NY, US: Cambridge University Press.

Schuurmans, I. K., Luik, A. I., de Maat, D., Hillegers, M. H. J., Ikram, M. A., Cecil, C. A. M. (2021). The influence of early life stress on IQ-achievement discrepancy in children: A population-based study. [Manuscript submitted for publication].

Sheidow, A. J., Henry, D. B., Tolan, P. H., \& Strachan, M. K. (2014). The role of stress exposure and family functioning in internalizing outcomes of urban families. Journal of Child and Family Studies, 23(8), 1351-1365. https://doi.org/10.1007/s10826-013-9793-3

Shonkoff, J. P. (2016). Capitalizing on advances in science to reduce the health consequences of early childhood adversity. JAMA pediatrics, 170(10), 1003-1007. https://doi.org/10.1001/jamapediat rics.2016.1559

Simpson, J. A., Griskevicius, V., Kuo, S. I., Sung, S., \& Collins, W. A. (2012). Evolution, stress, and sensitive periods: The influence of unpredictability in early versus late childhood on sex and risky behavior. Developmental Psychology, 48(3), 674-686. https://doi. org/10.1037/a0027293

Singh, A., Daniel, L., Baker, E., \& Bentley, R. (2019). Housing disadvantage and poor mental health: A systematic review. American Journal of Preventive Medicine, 57(2), 262-272. https://doi.org/ 10.1016/j.amepre.2019.03.018

Spagnola, M., \& Fiese, B. H. (2007). Family routines and rituals: A context for development in the lives of young children. Infants \& Young Children, 20(4), 284-299. https://doi.org/10.1097/01.IYC. $0000290352.32170 .5 \mathrm{a}$

Statistics Netherlands (2004). Allochtonen in Nederland 2004 [Foreigners in the Netherlands 2004]. Retrieved from http://www.cbs. $\mathrm{nl} / \mathrm{nl}$-NL/menu/themas/bevolking/publicaties/publicaties/archief/ 2004/2004-b52-pub.htm

Stoddard, S. A., Whiteside, L., Zimmerman, M. A., Cunningham, R. M., Chermack, S. T., \& Walton, M. A. (2013). The relationship between cumulative risk and promotive factors and violent behavior among urban adolescents. American Journal of Community Psychology, 51(1-2), 57-65. https://doi.org/10.1007/ s10464-012-9541-7

Stoppelbein, L., Biasini, F., Pennick, M., \& Greening, L. (2016). Predicting internalizing and externalizing symptoms among children diagnosed with an Autism Spectrum Disorder: The role of routines. Journal of Child and Family Studies, 25(1), 251-261. https://doi.org/10.1007/s10826-015-0218-3

Straus, M. A., Hamby, S. L., Finkelhor, D., Moore, D. W., \& Runyan, D. (1998). Identification of child maltreatment with the ParentChild Conflict Tactics Scales: Development and psychometric data for a national sample of American parents. Child Abuse and Neglect, 22, 249-270. https://doi.org/10.1016/S0145-2134(97) 00174-9

Suntheimer, N. M., \& Wolf, S. (2020). Cumulative risk, teacher-child closeness, executive function and early academic skills in kindergarten children. Journal of School Psychology, 78, 23-37. https:// doi.org/10.1016/j.jsp.2019.11.005

Sweeney, S., \& Macbeth, A. (2016). The effects of paternal depression on child and adolescent outcomes: A systematic review. Journal of Affective Disorders, 205, 44-59. https://doi.org/10.1016/j.jad. 2016.05.073

Thakur, H., \& Cohen, J. R. (2020). Short-term and long-term resilience among at-risk adolescents: The role of family and community settings. Journal of Clinical Child \& Adolescent Psychology, 1-14. https://doi.org/10.1080/15374416.2020.1756296

Van Buuren, S., \& Groothuis-Oudshoorn, K. (2011). "mice: Multivariate imputation by chained equations in R." Journal of Statistical Software, 45(3), 1-67. https://doi.org/10.18637/jss.v045.i03

Velders, F. P., Dieleman, G., Henrichs, J., Jaddoe, V. W. V., Hofman, A., Verhulst, F. C., Hudziak, J. J., \& Tiemeier, H. (2011). Prenatal and postnatal psychological symptoms of parents and family functioning: The impact on child emotional and behavioural problems. European Child \& Adolescent Psychiatry, 20(7), 341-350. https:// doi.org/10.1007/s00787-011-0178-0

Wallander, J. L., Berry, S., Carr, P. A., Peterson, E. R., Waldie, K. E., Marks, E., D'Souza, S., \& Morton, S. M. B. (2019). Patterns of exposure to cumulative risk through age 2 and associations with problems behaviors at age 4.5: Evidence from Growing up in New Zealand. Journal of Abnormal Child Psychology, 47, 1277-1288. https://doi.org/10.1007/s10802-019-00521-w

Wichstrøm, L., Berg-Nielsen, T. S., Angold, A., Egger, H. L., Solheim, E., \& Sveen, T. H. (2012). Prevalence of psychiatric disorders in preschoolers. Journal of Child Psychology and Psychiatry, 53(6), 695-705. https://doi.org/10.1111/j.1469-7610.2011.02514.x

Zimmerman, M. (2013). Resiliency theory: A strengths-based approach to research and practice for adolescent health. Health Education \& Behavior, 40(4), 381-383. https://doi.org/10.1177/1090198113 493782 